\title{
Pressure Pain Threshold in Depression: Is There a Difference between Unipolar and Bipolar Depressed Patients?
}

\author{
Özlem Kazan Kizilkurt ${ }^{1 *}$, Buket Niflioglu' ${ }^{2}$, Füsun Mayda Domaç ${ }^{3}$ and Sermin Kesebir ${ }^{4}$ \\ ${ }^{1}$ Department of Psychiatry, School of Medicine, University of Maltepe, Turkey \\ ${ }^{2}$ Muş State Hospital, Turkey \\ ${ }^{3}$ University of Health Sciences Erenköy Mental Research and Training Hospital, Turkey \\ ${ }^{4} N P$ Istanbul Neuropsychiatry Hospital, Üsküdar University, Turkey
}

*Corresponding author: Özlem Kazan KIzlkurt, Department of Psychiatry, School of Medicine, University of Maltepe, Atatürk Avenue, Çam Street, Number 3, 34843 Maltepe, Istanbul, Turkey, Tel: 00905065026186

\begin{abstract}
Objective: A complex relationship exists between mood and pain, which is supported by different pain tolerance in clinically depressed patients compared to healthy people. In the present study we aimed to investigate pressure pain threshold (PPT) in unipolar and bipolar depressed patients and assess any differences between these two diagnoses.

Method: This study included 40 patients diagnosed with unipolar depression and 89 patients diagnosed with bipolar depression according to DSM-IV criteria, also 40 healthy, age and gender-matched subjects without any known disease that could affect pain threshold were included in the study as a control group. PPT for mechanical pressure was examined by a handheld algometer at three body points. Student's t-test and analysis of variance was used to assess statistical differences between groups. The predictive level was investigated by univariate and multivariable linear regressions.
\end{abstract}

Results: Depressed patients had significantly higher PPT than that in controls, and bipolar depressed patients had significantly higher PPT than that in unipolar depressed patients. PPT was also significantly associated with gender and use of anticonvulsant drugs.

Conclusion: Bipolar patient group was observed to have higher pain thresholds than unipolar depression and control group in this study. Therefore, better understanding of the pain risk and burden of this group is an important step in improving the clinical outcomes of these patients.

\section{Keywords}

Pressure pain threshold, Unipolar depression, Bipolar depression

\section{Introduction}

Pain is described as an unpleasant sensory and emotional experience in association with potential or real tissue injury or described in terms of such damage; pain may also be described as acute or, if persisting longer than 3 to 6 months, as chronic [1]. A reciprocal association exists between emotions and pain such that interactions between mood and pain may vary from person to person or within the same individual across time in daily life [2].

Pain threshold is the minimal stimulus at which pain is perceived by an individual. Pain tolerance refers to the maximum duration of experiencing a painful stimulus, beyond which pain is no longer bearable [3]. Pressure pain threshold (PPT) reflects pain sensitivity and can be quantitatively measured using a mechanical or electronic pressure algometer [4], which has been reported to be a reliable, objective instrument $[5,6]$. Trigger points in the neck and shoulders are commonly used for measuring PPT, but PPT can also be measured in muscles without trigger points [7]. Assessing PPT at multiple points provides better reliability, particularly when all measurements are performed by the same examiner $[5,8]$. Furthermore, repeated algometric measurement does not change pain thresholds in healthy muscles [8].

Pain perception is thought to be the most important

Citation: Kizilkurt OK, Niflioglu B, Domaç FM, Kesebir S (2019) Pressure Pain Threshold in Depression: Is There a Difference between Unipolar and Bipolar Depressed Patients?. Int J Brain Disord Treat 5:028. doi.org/10.23937/2469-5866/1410028

Accepted: June 04, 2019: Published: June 06, 2019

Copyright: (c) 2019 Kizilkurt OK, et al. This is an open-access article distributed under the terms of the Creative Commons Attribution License, which permits unrestricted use, distribution, and reproduction in any medium, provided the original author and source are credited. 
mechanism of pain experience [9]. Pain perception and threshold show complex interactions with psychiatric and neuroendocrine stimuli; neurochemical and neurohormonal factors that control pain are thought to be affected by mental states. Specifically, a complex relationship has been proposed between pain and depression $[9,10]$. Several studies have investigated PPT and pain tolerance in depression, and depressed patients were found to have significantly lower PPT than that in healthy controls [10-12]. Following electroconvulsive therapy, both PPT and pressure pain tolerance values increased in depressed patients $[10,12]$. To the best of our knowledge, no study has compared PPT between unipolar and bipolar depression. Thus, the present study aimed to investigate PPT during depressed and remission periods in unipolar and bipolar depressed patients and assess any differences.

\section{Methods}

\section{Study group}

Forty patients diagnosed with unipolar depression and 89 patients diagnosed with bipolar depression were recruited from the mood disorders outpatient clinic of Erenköy Psychiatry and Neurological Diseases Training and Research Hospital, Istanbul, Turkey. Patients under treatment and diagnosed after a detailed clinical examination and structured interviews (the Structured Clinical Interview for DSM-IV Axis I Disorders: SCID-I) by experienced psychiatrists (authors) were included in the study. The control group comprised 40 healthy, age and gender-matched subjects without any known disease that could affect pain threshold. Exclusion criteria were patients below 18 years of age and with a history of acute or chronic metabolic, rheumatologic, neurological or endocrinological disease; alcohol abuse; mental retardation; cognitive impairment or any other psychiatric disease or any drug treatment that could affect pain perception. Patients were not simultaneously participating in any other studies. The study was approved by the local ethical committee, and all patients provided oral and written informed consent before participating.

\section{Study design}

PPT for mechanical pressure was examined by a handheld algometer through a circular, rubber-coated pressure probe $\left(1 \mathrm{~cm}^{2}\right)$. The trials were performed while the participants were instructed to lie down with their eyes closed. Participants were asked to report the onset of pressure pain. To assess PPT, three different points were selected: i) Proximal trapezius muscle; ii) Tibia and iii) Olecranon. The probe was pressed perpendicularly on the skin over the target structure. The pressure was increased by the investigator at a constant rate of 1 $\mathrm{kg} / \mathrm{s}$ until the subject signalled pain. Three trials were performed. After each trial, the footplate was moved slightly distally or proximally from the pre-existing pressure point to minimise local sensitisation. The mean value from the three trials was used as the threshold pressure. The trials were performed by the same investigator under similar physical conditions.

\section{Statistical analysis}

Statistical analysis was performed using SPSS version 22.0 software. Prior to analysis, the Kolmogorov Smirnov test was used to assess the distribution of the data. The mean, standard deviation, median, frequency and ratio values were used as descriptive statistics of the data. The statistical significance of between-group differences was assessed using the Student's $t$-test and analysis of variance. The predictive level was investigated by univariate and multivariable linear regressions. $P$ values $<0.05$ were considered statistically significant.

\section{Results}

The bipolar depression group included 63 female and 26 male patients with a mean age of $44.7 \pm 13.3$ years, whereas the unipolar depression group included 26 female and 14 male patients with a mean age of 47.2 \pm 14.2 years. The control group included 24 females and 14 males with a mean age of $41.3 \pm 8.9$ years. In the two depressed groups, 38 patients currently had depression (29.4\%), and 91 patients (70.6\%) were in remission. Fewer patients in the unipolar depression group (35\%) were in remission compared with those in the bipolar depression group (86.5\%). In the unipolar depression group, 36 patients $(90 \%)$ were receiving antidepressant treatment, and 4 patients (10\%) were receiving antiepileptic treatment. In the bipolar depression group, 49 patients $(55.1 \%)$ were receiving antidepressant treatment, 19 patients $(21.3 \%)$ were receiving lithium treatment and 51 patients (57.3\%) were receiving antiepileptic treatment; some patients were taking multiple types of medication.

Of the three points used to measure PPT, PPT at the tibia was significantly higher in the bipolar depression group than in the unipolar depression and control groups $(p<0.05)$. At the trapezius muscle, PPT was significantly higher in both the unipolar and bipolar depression groups than in the control group ( $p<0.05$ ); PPT at the trapezius muscle did not differ significantly between the unipolar and bipolar depression groups ( $p$ $>0.05$ ). At the olecranon, PPT was significantly higher in the bipolar depression group than in the unipolar depression and control groups $(p<0.05)$; PPT at the elbow did not differ significantly between the unipolar depression and control groups ( $p>0.05)$. Total PPT was significantly higher in the bipolar and unipolar depression groups than in the control group $(p<0.05)$. In addition, total PPT was significantly higher in the bipolar depression group than in the unipolar depression group $(p<$ 0.05, Table 1).

In this study, PPT was significantly lower in women than in men $(p=0.00)$ when patients in the unipolar 
Table 1: Total PPT was significantly higher in the bipolar depression group than in the unipolar depression group.

\begin{tabular}{|c|c|c|c|c|c|c|c|c|}
\hline & & & Control Group & & $\begin{array}{l}\text { Unipolar } \\
\text { Depression }\end{array}$ & & $\begin{array}{l}\text { Bipolar } \\
\text { Depression }\end{array}$ & $P$ Value \\
\hline \multicolumn{9}{|l|}{ PPT } \\
\hline \multirow[t]{2}{*}{ Tibia } & Mean \pm SD & \multirow[b]{2}{*}{25} & $26.4 \pm 8.0$ & \multirow[b]{2}{*}{30} & $30.7 \pm 8.6$ & \multirow[b]{2}{*}{36} & $35.7 \pm 9.4$ & \multirow[b]{2}{*}{$0.00^{A}$} \\
\hline & Median (Min-Max) & & $15.0-52.0$ & & $19.0-52.0$ & & $8.0-63.0$ & \\
\hline \multirow{2}{*}{$\begin{array}{l}\text { Trapezius } \\
\text { Muscle }\end{array}$} & Mean \pm SD & \multirow[b]{2}{*}{16} & $18.5 \pm 7.3$ & \multirow[b]{2}{*}{25} & $25.1 \pm 8.5$ & \multirow[b]{2}{*}{27} & $27.5 \pm 8.3$ & \multirow[b]{2}{*}{$0.00^{A}$} \\
\hline & Median (Min-Max) & & $10.0-43.0$ & & $5.0-44.0$ & & $8.0-52.0$ & \\
\hline \multirow[t]{2}{*}{ Olecranon } & Mean \pm SD & \multirow[b]{2}{*}{21} & $22.5 \pm 6.2$ & \multirow[b]{2}{*}{28} & $27.5 \pm 8.1$ & \multirow[b]{2}{*}{32} & $32.6 \pm 10.1$ & \multirow[b]{2}{*}{$0.00^{A}$} \\
\hline & Median (Min-Max) & & $16.0-43.0$ & & $14.0-44.0$ & & $12.0-55.0$ & \\
\hline \multirow[t]{2}{*}{ Total } & Mean \pm SD & \multirow[b]{2}{*}{63} & $67.3 \pm 18.3$ & \multirow[b]{2}{*}{82} & $83.3 \pm 19.5$ & \multirow[b]{2}{*}{94} & $95.8 \pm 21.7$ & \multirow[b]{2}{*}{$0.00^{A}$} \\
\hline & Median (Min-Max) & & $51.0-138.0$ & & $46.0-120.0$ & & $38.0-150.0$ & \\
\hline
\end{tabular}

PPT: Pressure Pain Threshold; AANOVA (Turkey test).

Table 2: Mean PPT was significantly higher in patients using anticonvulsant drugs.

\begin{tabular}{|c|c|c|c|c|c|}
\hline & \multicolumn{5}{|l|}{ PPT } \\
\hline & & Min-mam & Medium & Mean \pm SD & $P$ value \\
\hline \multirow[t]{2}{*}{ Gender } & Woman & $38-134$ & 83 & $83.6 \pm 21.3$ & \multirow[t]{2}{*}{0.00} \\
\hline & Man & $58-150$ & 100 & $100.5 \pm 22.3$ & \\
\hline \multirow[t]{2}{*}{ State } & Depression & $56-126$ & 90 & $91.2 \pm 18.1$ & \multirow[t]{2}{*}{0.73} \\
\hline & Remission & $38-150$ & 92 & $92.3 \pm 23.2$ & \\
\hline \multirow[t]{2}{*}{ Antidepressant Usage } & Yes & $38-148$ & 89 & $88.6 \pm 20.8$ & \multirow[t]{2}{*}{0.93} \\
\hline & No & $45-150$ & 92 & $88.6 \pm 25.5$ & \\
\hline \multirow[t]{2}{*}{ Lithium Usage } & Yes & $45-148$ & 97 & $97.1 \pm 25.9$ & \multirow[t]{2}{*}{0.08} \\
\hline & No & $38-150$ & 88 & $87.4 \pm 22.2$ & \\
\hline \multirow[t]{2}{*}{ Anticonvulsant Usage } & Yes & $45-150$ & 94 & $95.5 \pm 21.8$ & \multirow[t]{2}{*}{0.01} \\
\hline & No & $38-138$ & 82 & $84.7 \pm 22.6$ & \\
\hline
\end{tabular}

PPT: Pressure Pain Threshold; Independent t-test.

Table 3: Were again found to have a significant and independent effect on PPT.

\begin{tabular}{|l|l|l|l|l|}
\hline & \multicolumn{3}{|l|}{$\begin{array}{l}\text { Univariate } \\
\text { Model }\end{array}$} & \multicolumn{2}{l|}{$\begin{array}{l}\text { Multivariate } \\
\text { Model }\end{array}$} \\
\hline & $\boldsymbol{\beta}$ & $\boldsymbol{P}$ value & $\boldsymbol{\beta}$ & $\boldsymbol{P}$ value \\
\hline Age & 0.06 & 0.43 & & \\
\hline Gender & 0.34 & $\mathbf{0 . 0 0}$ & 0.27 & 0.00 \\
\hline State & 0.02 & 0.79 & & \\
\hline Antidepressant usage & 0.00 & 1.00 & & \\
\hline Lithium usage & -0.14 & 0.09 & & \\
\hline Anticonvulsant usage & -0.23 & $\mathbf{0 . 0 1}$ & -0.17 & 0.05 \\
\hline
\end{tabular}

Linear Regression.

and bipolar groups were stratified according to gender (89 women, 40 men). When patients were stratified according to the depression and remission status, there was no significant difference in PPT between the two states $(p>0.05)$. While PPT did not significantly differ with antidepressant or lithium use $(p>0.05)$, it was observed that the mean PPT was significantly higher in patients using anticonvulsant drugs than in those who did not ( $p=0.01$, Table 2).

To investigate the predictive effect of age, gender, disease status and use of antidepressant, lithium or anticonvulsant drugs on PPT, a univariate regression model was initially established. In the model, gender $(\beta$ $=0.34, p=0.00)$ and use of anticonvulsant drugs $(\beta=$ $-0.23, p=0.01$ ) showed a significant effect on PPT. The same variables were then examined in a multivariate model, wherein gender $(\beta=0.27, p=0.00)$ and use of anticonvulsant drugs $(\beta=-0.17, p=0.05$ ) were again found to have a significant and independent effect on PPT (Table 3).

\section{Discussion}

This is the first study to compare the pain threshold between patients with unipolar depression and those with bipolar depression and to examine the differences with healthy controls. There is evidence that there is a close relationship between pain regulation and various psychiatric disorders, that mood affects pain perception and pain tolerance and particularly that pain is an important characteristic of depression [13,14]. Clinical observations in patients suffering from depression and those suffering from chronic pain have indicated that the two conditions are interrelated [15-17]. The pain-depression association is also supported by a neuroinflammatory 
link because increased values of IL6, IL1 $\beta$ and BDNF are found in both $[18,19]$. Studies evaluating pain threshold in patients diagnosed with depression have shown different results. Some studies have shown elevated pain threshold in patients with depression $[20,21]$, whereas others have shown decreased pain threshold in these patients [12,22]. Although the relationship between pain threshold and depression remains unclear, the above-mentioned findings suggest that pain perception in patients with depression is different from that in healthy controls. In our study, total pain threshold was significantly higher in the bipolar and unipolar depression groups than in the healthy control group. This result is consistent with those of a similar previous study. Davis, et al. compared 76 patients with bipolar and unipolar mood disorder with 48 control subjects using the psychophysical pain assessment method involving both pain threshold and signal perception analyses and found that the patients were more analgesic than control subjects [23].

In this study, when the pain thresholds were compared between patients with bipolar depression and those with unipolar depression, the total pain threshold was significantly higher in the bipolar depression group than in the unipolar depression group. Only few studies have evaluated pain perception in bipolar disorder, particularly comparing pain threshold in bipolar and unipolar depression, and our results differ from those of some studies on mood disorders. In a study evaluating thermal pain sensitivity in bipolar and depressed individuals, it was reported that the bipolar disorder group did not significantly differ from the major depression or control groups in terms of sensory differentiation [24]. However, by definition, pain is always considered subjective; it depends on emotional and cognitive factors and is also influenced by long-term changes in the emotional state. In patients with bipolar disorders, a physiological dysfunction may affect the transmission of pain stimuli. A number of mechanisms modulate the processing of mood and noxious information, and psychiatric disorder processes may affect neuro-psychobiological systems in pain signalling regulated by adrenergic, serotonergic and opioidergic activities [9].

A significant portion of the literature indicates that patients suffering from chronic pain have higher rates of depression and anxiety symptoms than those without chronic pain $[25,26]$. Nevertheless, the prevalence of chronic pain in patients with severe mental illnesses such as schizophrenia and bipolar disorder has received little attention $[27,28]$. Patients with mental illnesses such as schizophrenia and bipolar disorder are at a high risk for painful physical illnesses including cardiopulmonary diseases, metabolic diseases, bone diseases, viral infections and cancer $[29,30]$, and pain is associated with the worsening of psychiatric symptoms in these patients [27]. Furthermore, such patients are more likely to experience pain-related conditions than those without these illnesses; at the same time, they are less likely to receive adequate care to manage this [29,31]. A recent systematic review has shown that patients with schizophrenia, who have a higher pain threshold than the general population, have a lower prevalence of pain than those with other psychiatric disorders, particularly bipolar disorder [32]. However, to date, individuals diagnosed with bipolar disorder have been considered to have a lower probability of receiving medical assistance, but the data evaluating pain perception are limited [28]. A systematic review that assessed the prevalence of pain in bipolar disorder in a large-scale meta-analysis revealed that individuals with bipolar disorder have higher levels of pain than healthy controls [33]. Although bipolar patient group was observed to have higher pain thresholds than unipolar depression and control group in this study, these patients have a higher pain level than the general population, and a better understanding of the pain risk and burden of this group is an important step in improving the clinical outcomes of these patients. In addition, bipolar disorder leads to serious deficits in global functioning and is considered by the World Health Organisation (WHO) to be a Top 10 cause of disability across the world. Studies have reported that chronic pain affects function and quality of life negatively in these patients [34,35]. Especially in the bipolar group, which is a chronic disease, we think that accurate assessment of the pain may increase the quality of life and functionality of the patients.

Gender-related differences in experiencing both clinically and experimentally induced pain have been reported [36-38]. In particular, women are at a greater risk for developing chronic pain disorder and more susceptible to pain stimuli under laboratory conditions than are men [39]. Various mechanisms have been proposed to explain these gender differences, including psychosocial factors such as sex role [40], pain coping strategies [41] and mood [42], as well as familial factors [43] and sex hormones [44]. Similarly, studies on patients with depression have found lower pain thresholds in women with depression have $[13,20]$. In our study, which evaluated pain thresholds in unipolar and bipolar depression, we found that pain threshold was significantly lower in women than in men. Similarly, in a study by Davis, et al. examining pain thresholds in patients with affective disease, men with depression were found to be significantly more analgesic than women with depression [23].

When the patient group was divided into two groups as depression and remission, no cross-sectional difference was observed in terms of pain threshold in patients in both groups. In addition to studies reporting that pain threshold returns to normal values after the depressive symptoms are relieved in patients with depression [20,45], Gormsen, et al. compared pain thresholds before and after ECT treatment in patients with depression and reported no significant differences [10]. However, Davis, et al. suggested that patients with both 
unipolar and bipolar disorders have reduced experimental pain sensitivity, which is relatively independent of mood [23]. We believe that there is a need for controlled and longitudinal studies to make a more detailed assessment in this regard.

In our study, we aimed to evaluate the effect of medication used by the patient group on pain threshold and found that pain threshold did not differ between patients who used antidepressant drugs and lithium and those who did not. It has been reported that pain and depression are interrelated with one or several biological mechanisms and changes in the serotonergic and catecholaminergic neurotransmission are probable candidates for neurochemical mechanisms that are common between pain and depression [45]. Tricyclic antidepressants have been used for several years to relieve various types of neuropathic pain in patients with chronic pain with or without clinical depression, and serotonin and noradrenaline reuptake inhibitors are known to relieve pain in painful neuropathy [12]. However, a review on mood stabilising drugs concluded that there is no evidence that monoamine oxidase inhibitors or lithium carbonate has an analgesic effect on experimental or acute clinical pain [46]. In the same review, it was concluded that although antidepressants had an analgesic effect in chronic pain, the evidence for analgesic effects in experimental or acute clinical pain was contradictory [47]. In our study, we evaluated the effect of anticonvulsants, which are another type of medication used by patients, on pain threshold and found that pain threshold was significantly higher in patients using anticonvulsant drugs than in those not using anticonvulsant drugs and the use of anticonvulsant drugs predicted the increase in pain threshold in the regression model established. Anticonvulsants are effective drugs for the treatment of trigeminal neuralgia, diabetic neuropathy and migraine recurrence [48]. Phentoine [49], carbamazepine [50] and valproic acid [51] are used in the treatment of neuropathic pain, with a proven effect. The effect of anticonvulsant drugs on pain occurs via the stabilisation of pre-synaptic neuronal membranes by blocking the activity of sodium channels, reducing the release of excitatory neurotransmitters and reducing the spontaneous firing of damaged or healing nociceptive fibres.

\section{Limitations}

The main limitation of this study was a possible interaction between the pain perception and drugs used by patients during the study. Patients received mood stabilisers and antidepressant medications during the study period. Previous clinical studies have shown that mood stabilisers, antidepressants, benzodiazepines and antipsychotic drugs have analgesic effects [52,53]. Because psychotropic drugs may have an effect on pain sensitivity, it is important to assess the likelihood of the present results reflecting such drug effects; however, the dis- continuation of patient medication for research purposes is unethical. In particular, the use of mood stabilising drugs only in the bipolar disorder patient group may also have affected the results. Because mood stabilising agents have analgesic properties, an effect on pain sensitivity can be expected. There is a need for controlled, longitudinal studies to determine the relative effects of psychiatric medicines on patients' pain experience.

\section{Role of Funding Sources}

Funding for this study was provided by the authors. No funding body contributed to the study.

\section{The Conflict of Interest}

For all authors, there is no conflict of interest including any financial, personal or other relationships with other people or organizations within three (3) years of beginning the work submitted that could inappropriately influence, or be perceived to influence, their work.

\section{Acknowledgement}

There are no any acknowledgements.

\section{Author's Contributions}

OKK, BN, FMD, SK designed the study, wrote the protocol. OKK and FMD managed the literature searches and collected data. OKK conducted the statistical analysis. OKK and FMD wrote the first draft of manuscript. All authors contributed to and have approved the final manuscript.

\section{References}

1. Merskey H (1989) Psychiatry and chronic pain. Can J Psychiatry 34: 329-336.

2. Graham-Engeland JE, Zawadzki MJ, Slavish DC, Smyth JM (2016) Depressive symptoms and momentary mood predict momentary pain among rheumatoid arthritis patients. Ann Behav Med 50: 12-23.

3. Fischer AA (1987) Pressure algometry over normal muscles. Standard values, validity and reproducibility of pressure threshold. Pain 30: 115-126.

4. Castien RF, Van der Wouden JC, De Hertogh W (2018) Pressure pain thresholds over the cranio-cervical region in headache: a systematic review and meta-analysis. J Headache Pain 19: 9.

5. Kosek E, Ekholm J, Nordemar R (1993) A comparison of pressure pain thresholds in different tissues and body regions. Long-term reliability of pressure algometry in healthy volunteers. Scand J Rehabil Med 25: 117-124.

6. Ylinen J, Nykänen M, Kautiainen H, Häkkinen A (2007) Evaluation of repeatability of pressure algometry on the neck muscles for clinical use. Man Ther 12: 192-197.

7. Potter L, McCarthy C, Oldham J (2006) Algometer reliability in measuring pain pressure threshold over normal spinal muscles to allow quantification of anti-nociceptive treatment effects. International Journal of Osteopathic Medicine 9: 113-119.

8. Nussbaum EL, Downes L (1998) Reliability of clinical pressure-pain algometric measurements obtained on 
consecutive days. Phys Ther 78: 160-169.

9. Lautenbacher S, Krieg JC (1994) Pain perception in psychiatric disorders: A review of the literature. J Psychiatr Res 28: 109-122.

10. Gormsen L, Ribe AR, Raun P, Rosenberg R, Videbech $P$, et al. (2004) Pain thresholds during and after treatment of severe depression with electroconvulsive therapy. Eur $\mathrm{J}$ Pain 8: 487-493.

11. Merskey H, Evans PR (1975) Variations in pain complaint threshold in psychiatric and neurological patients with pain. Pain 1: 73-79.

12. Schreiber S, Shmueli D, Grunhaus L, Dolberg OT, Feldinger $E$, et al. (2003) The influence of electroconvulsive therapy on pain threshold and pain tolerance in major depression patients before, during and after treatment. Eur $\mathrm{J}$ Pain 7: 419-424.

13. von Knorring L, Espvall M (1974) Experimentally induced pain in patients with depressive disorders. Acta Psychiat Scand Suppl 255: 121-133.

14. Hemphill RE, Crookes TG (1951) A preliminary report on fatigue and pain tolerance in depressive and psychoneurotic patients. J Ment Sci 98: 433-440.

15. Gupta MA (1986) Is chronic pain a variant of depressive illness? A critical review. Can J Psychiatry 31: 241-248.

16. France RD (1987) Chronic pain and depression. J Pain Symptom Manage 2: 234-236.

17. Magni G (1987) On the relationship between chronic pain and depression when there is no organic lesion. Pain 31 $1-21$.

18. Doan L, Manders T, Wang J (2015) Neuroplasticity underlying the comorbidity of pain and depression. Neural Plast 2015: 504691.

19. Burke NN, Finn DP, Roche M (2015) Neuroinflammatory mechanisms linking pain and depression. Mod Trends Pharmacopsychiatry 30: 36-50.

20. von Knorring $L$ (1974) An intraindividual comparison of pain measures averaged evoked responses and clinical ratings during depression and after recovery. Acta Psychiat Scand Suppl 255: 109-120.

21. Lautenbacher S, Spernal J, Schreiber W, Krieg JC (1999) Relationship between clinical pain complaints and pain sensitivity in patients with depression and panic disorder. Psychosom Med 61: 822-827.

22. Merskey $H$ (1965) The effect of chronic pain upon the response to noxious stimuli by psychiatric patients. J Psychosom Res 8: 405-419.

23. Davis GC, Buchsbaum MS, Bunney WE (1979) Analgesia to painful stimuli in affective illness. Am J Psychiatry 136: 1148-1151.

24. Dworkin RH, Clark WC, Lipsitz JD (1995) Pain responsivity in major depression and bipolar disorder. Psychiatry Res 56: 173-181.

25. Arnow BA, Hunkeler EM, Blasey CM, Lee J, Constantino MJ, et al. (2006) Comorbid depression, chronic pain, and disability in primary care. Psychosom Med 68: 262-268.

26. Means-Christensen AJ, Roy-Byrne PP, Sherbourne CD, Craske MG, Stein MB (2008) Relationships among pain, anxiety, and depression in primary care. Depress Anxiety 25: 593-600.

27. Elman I, Zubieta JK, Borsook D (2011) The missing $p$ in psychiatric training: Why it is important to teach pain to psychs. Arch Gen Psychiatry 68: 12-20

28. Birgenheir DG, Ilgen MA, Bohnert ASB, Abraham KM, Bowersox NW, et al. (2013) Pain conditions among veterans with schizophrenia or bipolar disorder. Gen Hosp Psychiatry 35: 480-484.

29. DE Hert M, Correll CU, Bobes J, Cetkovich-Bakmas M, Cohen D, et al. (2011) Physical illness in patients with severe mental disorders. I. Prevalence, impact of medications and disparities in health care. World Psychiatry 10: 52-77.

30. Prieto ML, Cuéllar-Barboza $A B$, Bobo WV, Roger VL, Bellivier F, et al. (2014) Risk of myocardial infarction and stroke in bipolar disorder: A systematic review and exploratory meta-analysis. Acta Psychiatr Scand 130: 342353.

31. Leucht S, Burkard T, Henderson J, Maj M, Sartorius N (2007) Physical illness and schizophrenia: A review of the literature. Acta Psychiatr Scand 116: 317-333.

32. Engels G, Francke AL, van Meijel B, Douma JG, de Kam $\mathrm{H}$, et al. (2004) Clinical pain in schizophrenia: A systematic review. J Pain 15: 457-467.

33. Stubbs B, Eggermont L, Mitchell AJ, De Hert M, Correll $\mathrm{CU}$, et al. (2015) The prevalence of pain in bipolar disorder: A systematic review and large-scale meta-analysis. Acta Psychiatr Scand 131: 75-88.

34. Arnold LM, Witzeman KA, Swank ML, McElroy SL, Keck Jr PE (2000) Health-related quality of life using the SF-36 in patients with bipolar disorder compared with patients with chronic back pain and the general population. $J$ Affect Disord 57: 235-239.

35. Miller CJ, Abraham KM, Bajor LA, Lai Z, Kim HM, et al. (2013) Quality of life among patients with bipolar disorder in primary care versus community mental health settings. J Affect Disord 146: 100-105.

36. LeResche L (1999) Gender considerations in the epidemiology of chronic pain. In: Crombie IK, Epidemiology of Pain. IASP Press, Seattle, 43-52.

37. Unruh AM (1996) Gender variations in clinical pain experience. Pain 65: 123-167

38. Fillingim RB, Maixner W (1995) Gender differences in the responses to noxious stimuli. Pain Forum 4: 209-221.

39. Fillingim RB (2000) Sex, gender, and pain: women and men really are different. Curr Rev Pain 4: 24-30.

40. Otto MW, Dougher MJ (1985) Sex differences and personality factors in responsivity to pain. Percept Mot Ski 61: 383-390

41. Geisser ME, Robinson ME, Pickren WE (1992) Differences in cognitive coping strategies among pain-sensitive and pain-tolerant individuals on the cold-pressor test. Behavior Therapy 23: 31-41.

42. Zelman DC, Howland EW, Nichols SN, Cleeland CS (1991) The effects of induced mood on laboratory pain. Pain 46: 105-111.

43. Edwards PW, Zeichner A, Kuczmierczyk AR, Boczkowski $\mathrm{J}$ (1985) Familial pain models: the relationship between family history of pain and current pain experience. Pain 21 : 379-384.

44. Fillingim RB, Ness TJ (2000) Sex-related hormonal influences on pain and analgesic responses. Neurosci Biobehav Rev 24: 485-501.

45. Otto MW, Dougher MJ, Yeo RA (1989) Depression, pain, 
and hemispheric activation. J Nerv Ment Dis 177: 210-218.

46. Atkinson JH (1989) Psychopharmacologic agents in the treatment of pain syndromes. In: Tollison, CD, Handbook of chronic pain management. Williams \& Wilkins Co., Baltimore, 69-103.

47. Fürst S (1999) Transmitters involved in antinociception in the spinal cord. Brain Res Bull 48: 129-141.

48. Roose SP, Glassman AH, Siris S, Walsh BT, Bruno RL (1981) Comparison of imipramine and nortriptyline-induced orthostatic hypotension: A meaningful difference. J Clin Psychopharmacol 1: 316-319.

49. Bergouignan M (1942) Cures heureuses de nevralgies faciaales essentielles par le diphenyl-hydantoinate de soude. Rev Laryngol Otol Rhinol 63: 34-41.
50. Tanelian DL, Victory RA (1995) Sodium channel-blocking agents: Their use in neuropathic pain conditions. Pain Forum 4: 75-89.

51. Jensen R, Brinck T, Olesen J (1994) Sodium valproate has a prophylactic effect in migraine without aura: A triple-blind, placebo-controlled crossover study. Neurology 44: 647647.

52. Marazziti D, Mungai F, Vivarelli L, Presta S, Dell'Osso B (2006) Pain and psychiatry: A critical analysis and pharmacological review. Clin Pract Epidemiol Ment Heal 2: 31.

53. Schreiber S, Getslev V, Backer MM, Weizman R, Pick CG (1999) The atypical neuroleptics clozapine and olanzapine differ regarding their antinociceptive mechanisms and potency. Pharmacol Biochem Behav 64: 75-80. 